\title{
TRAZO, PROPORCIÓN Y SIMBOLO EN LA CATEDRAL DE MORELIA
}

Manuel González Galván

\section{Algunos datos cronológicos del edificio actual}

La catedral de Valladolid fue una de las empresas arquitectónicas más ambiciosas del siglo XVII novohispano.

Correspondió al obispo fray Marcos Ramírez del Prado iniciar las obras del templo actual, después de que el 2 de marzo de 1660 el virrey duque de Alburquerque mandó que se ejecutara la obra conforme a la traza del arquitecto, venido de Italia, Vicenzo Baroccio de la Escayola, quien terminó por llamarse en estas tierras Vicente Barroso; él dirigió la obra hasta su muerte, acaecida por 1695 , dejando desplantado el templo y cubierto en la cabecera, pero sin cúpula ni portadas ni torres. Le siguió en el cargo Juan de Silva hasta 1709, año en que éste murió, y luego Lucas Durån; finalmente, José de Medina concluyó el conjunto con la edificación de las fachadas y torres; la torre del poniente lleva la fecha de 1742 y en la fachada principal se anota la de 1744, año en que el obispo Don Francisco Pablo Matos Coronado, quien impulsó la terminación de la obra, murió el 26 de abril.

Duró así la construcción de la catedral un lapso de 84 años y tuvo dos dedicaciones: la primera el 10 de mayo de 1705 , al considerarse concluida y apto litúrgicamente el interior, y la segunda el 9 de mayo de 1745, cuando se completó el exterior como hoy lo vemos.

La parva síntesis cronológica que apuntamos calla, en razón de la brevedad, pero sin dejar de rendirles tributo, los nombres de dignísimos prelados que se preocuparon por la realización y dignificación del templo, de insignes alarifes, artistas y artesanos, conocidos unos, ignorados los más, que aportaron su genio para tiansformar lo inerte de la materia en noble expresión artística que superó dificultades y limitaciones de toda índole -en lo temporal, en lo económico, en lo social一, para heredarnos este rostro y corazón de la ciudad, que es la catedral, monumento máximo y óptimo fruto estético en ella por consecuencia del aglutinamiento logrado secularmente por la fe. 


\section{La estructura}

Cabe anotar que el monumento está integramente construido con la hermosa y resistente cantera moreliana de proverbiales tonos de rosa y violáceo. La loma en que se asienta la ciudad es un enorme banco de piedra, por lo que el subsuelo no presenta problemas de cimentación y la cantera necesaria para la construcción del templo debió extraerse principalmente de cortes en la parte nororiente de la misma loma.

Como medidas generales el edificio tiene, incluyendo el espesor de los muros, 77.10 metros de largo por 30.50 metros de ancho en el crucero.

Interiormente, la nave mayor y crucero se levantan a 19.60 metros de altura hasta el intradós de las bóvedas, en tanto que las naves laterales se elevan a 14.15 metros, igualmente al intradós de sus bóvedas. La cúpula llega a los 40 metros hasta la cruz de remate.

Exteriormente, la fachada principal y las de los cruceros tienen 23.30 metros hasta su remate central y las torres alcanzan los 66.80 metros, incluyendo la cruz, por lo que pueden considerarse las más corpulentas y altas, entre las de estilo barroco, de todo el continente (láms. 1 y 6).

La planta se distribuye y cubre en la siguiente forma: tres naves longitudinales, una central mayor y dos procesionales, con siete tramos transversales y un crucero, dispuestos cuatro tramos antes de éste y tres después hacia la cabecera. Naves y tramos van separados por catorce grandes pilares aislados e iguales en dos filas longitudinales de siete pilares cada una. Los pilares se forman en cruz acentuada por el adosamiento de cuatro pilastras cada uno, con sus correspondientes pilastras fronteras en todo el perímetro interior del templo.

La cubierta se organiza en forma simétrica y central a partir 'de la cúpula, con todos los espacios internos a ella referidos.

La cúpula pasa del desplante cuadrado de sus cuatro arcos torales al ochavo exterior del tambor, que por dentro es circular, para recibir el espacio esférico de la media naranja; hábil y refinado paso paulatino del cubo a la esfera en combinada simbiosis y solución poco usual, aunque con un antecedente tan distinguido como lo es la cúpula de la catedral de Puebla, construida al mediar el siglo XVII.

De la cúpula irradian, descendiendo simétricamente, diez bóvedas de lunetos; cuatro hacia la cabecera (altar y ábside), cuatro hacia la entrada (antes sitio del coro) y una a cada lado (brazos del crucero). En seguida, siete bóvedas de arista por cada nave lateral, cuatro antes del crucero y tres después, que remansan y presionan las perspectivas hacia los retablos de remate para que, finalmente, en los cuatro extremos de la construcción 


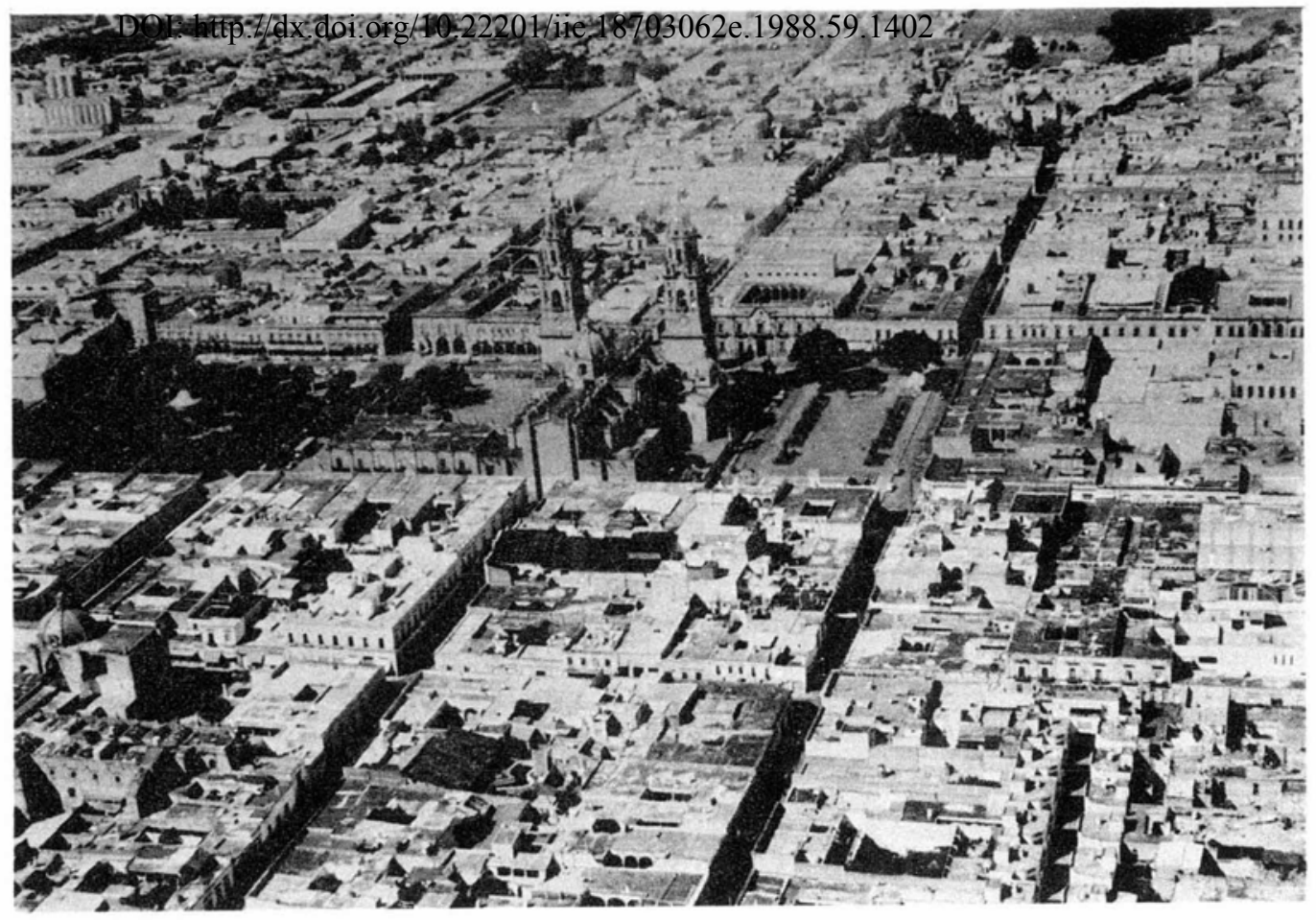

Figura 1. Centro urbano de Morelia definido con la presencia catedralicia.

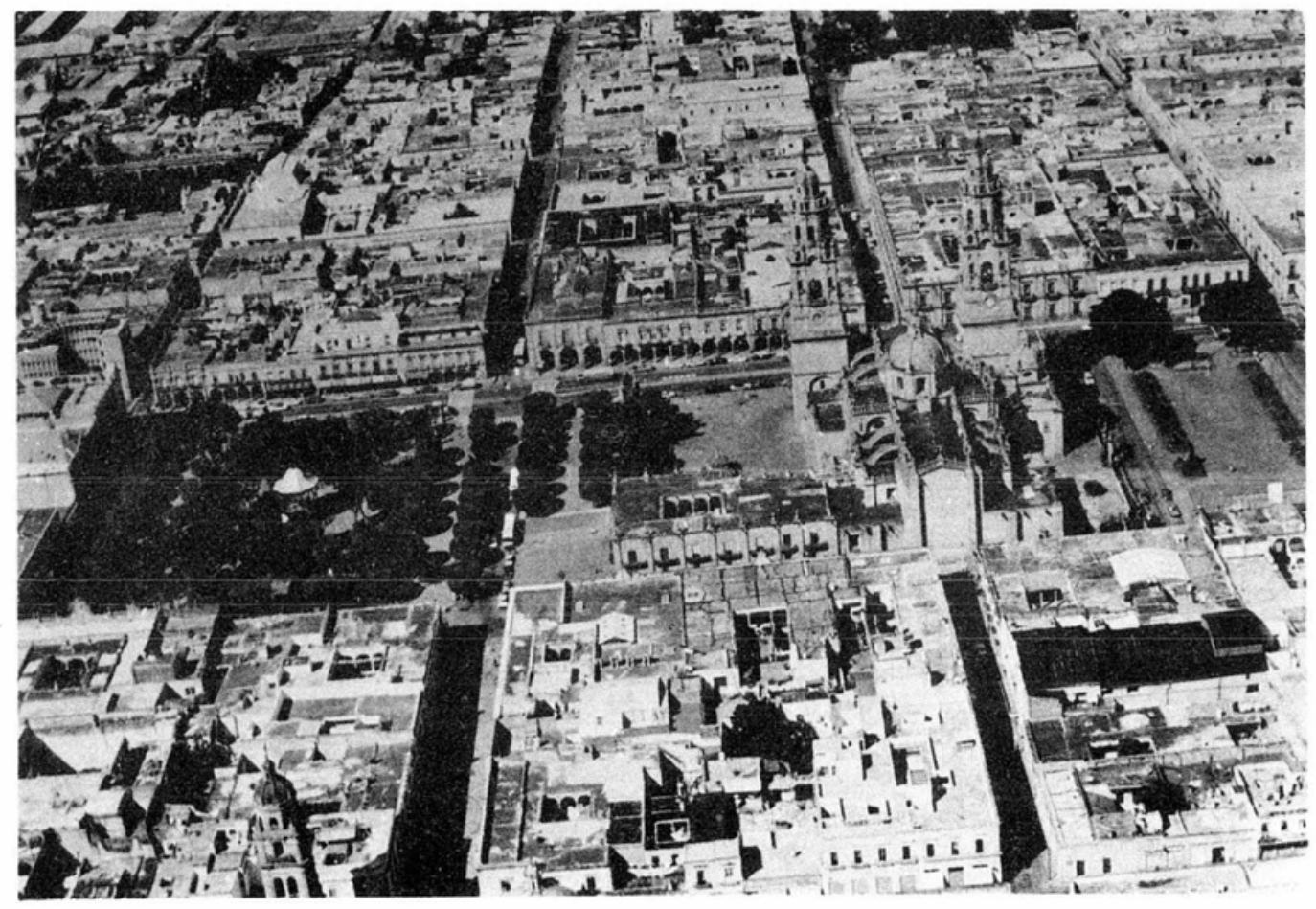

Figura 2. El gran espacio abierto subdividido armónicamente por la catedral en dos plazas de distinta dimensión, la mayor con portales en todo su perímetro, la menor circundada con paramentos planos. 


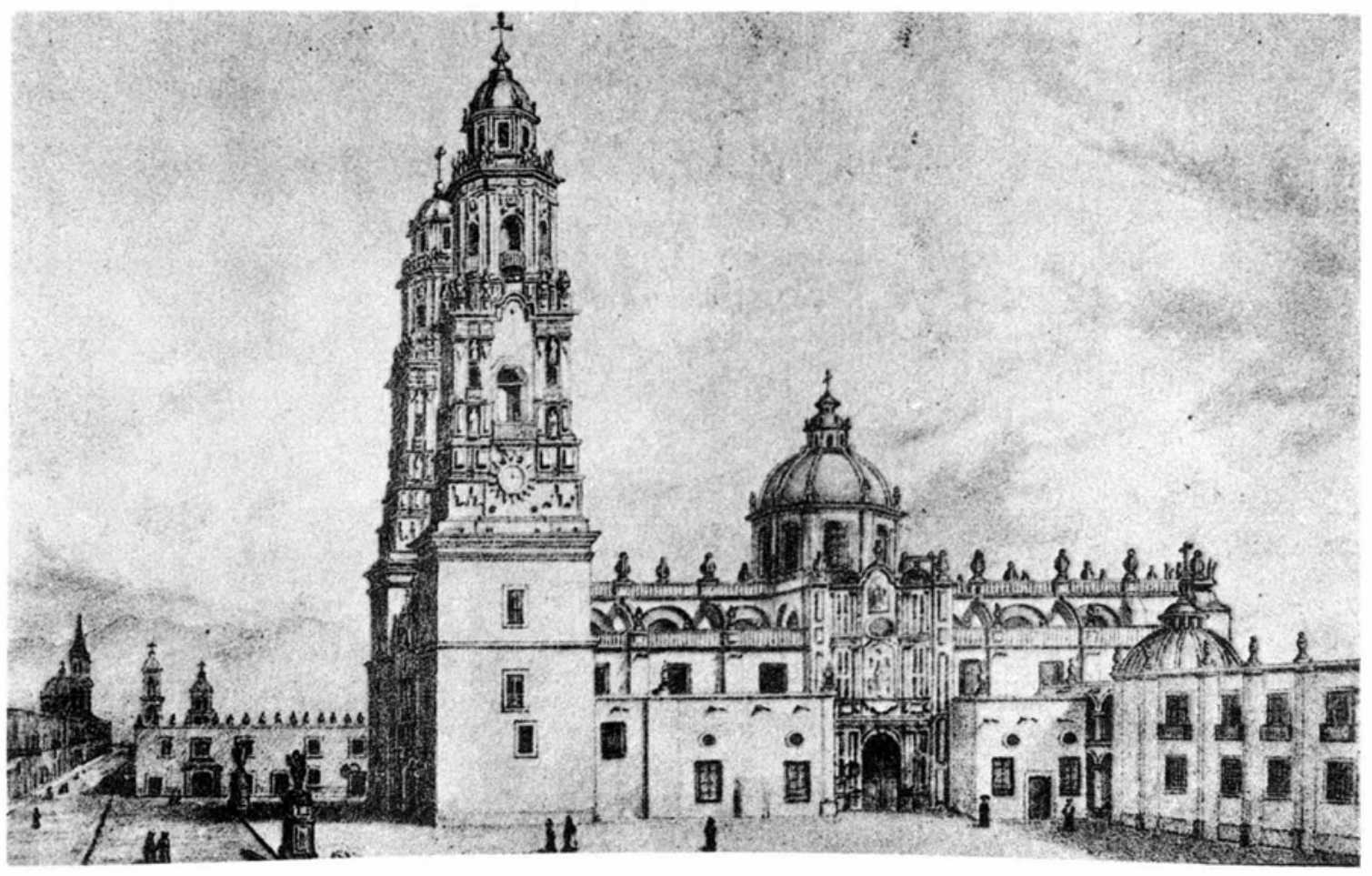

Figura 3. La catedral, en su costado poniente, vé a la Plaza Mayor, en tanto la fachada principal tiene un escaso atrio frontero. 
DOI: http://dx.doi.org/10.22201/iie.18703062e.1988.59.1402

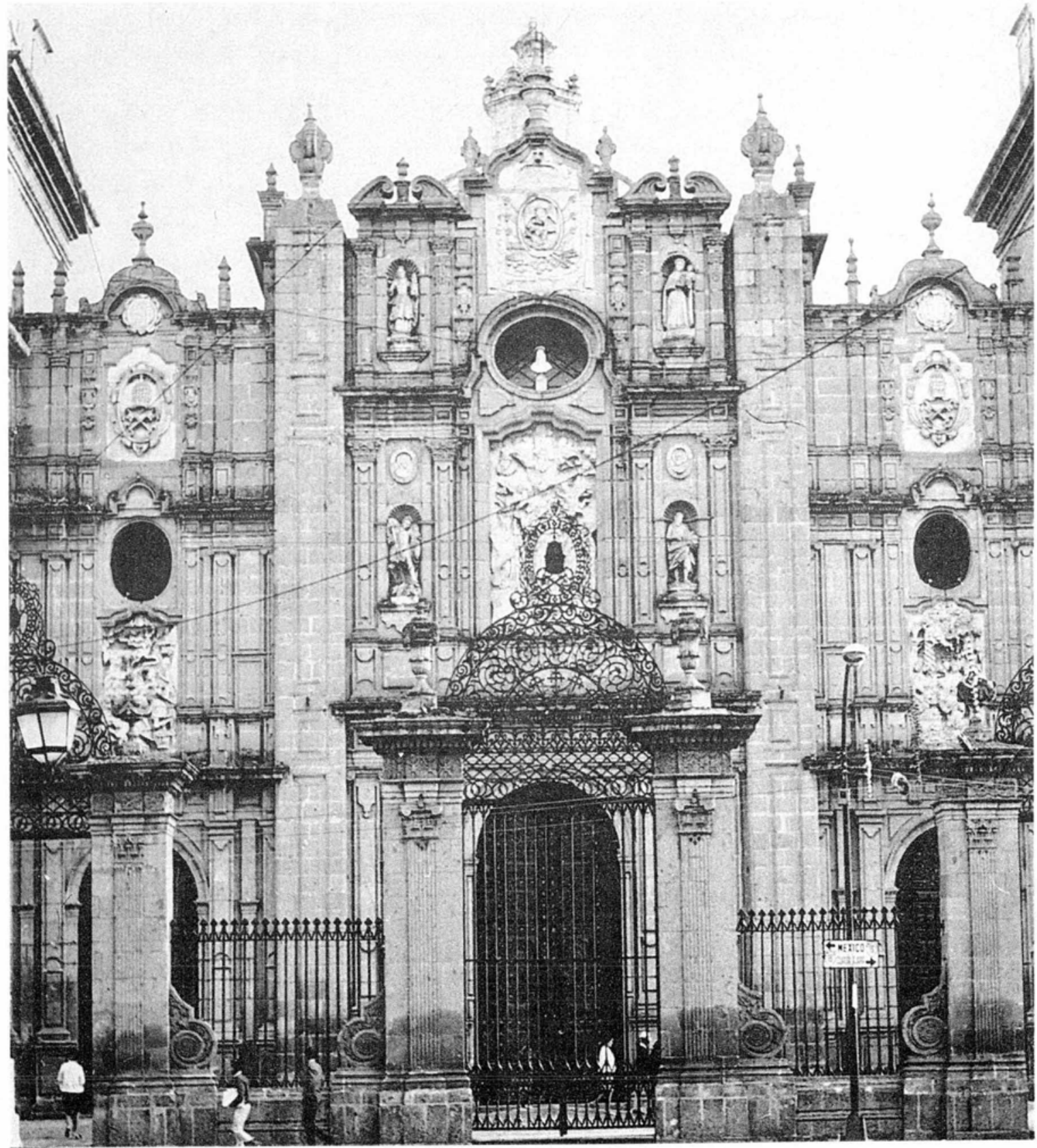

Figura 4. Fachada principal de la catedral que con la brevedad de su atrio obliga al espectador a una mayor aproximación a su expresión plástica e imaginería y, por tanto, a su mensaje simbólico. 


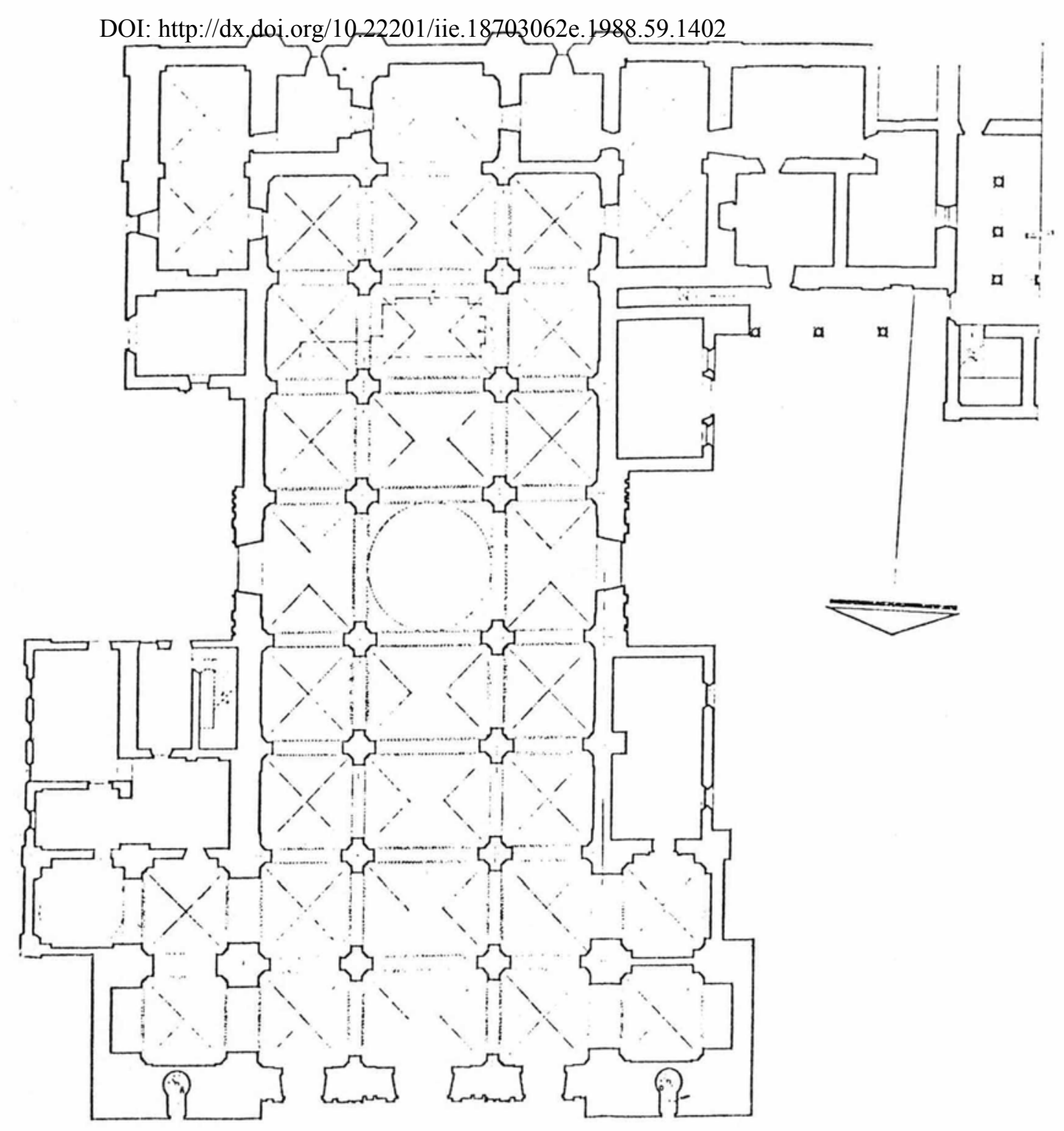

Lámina 1. Planta de la catedral en la nitidéz de su esquema estructural, distribución de espacios y sistema de cubierta. 


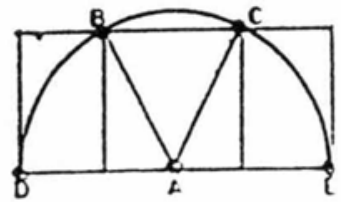

figuro $n^{\circ}$

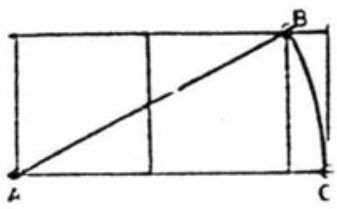

flguro $n^{\circ} 2$

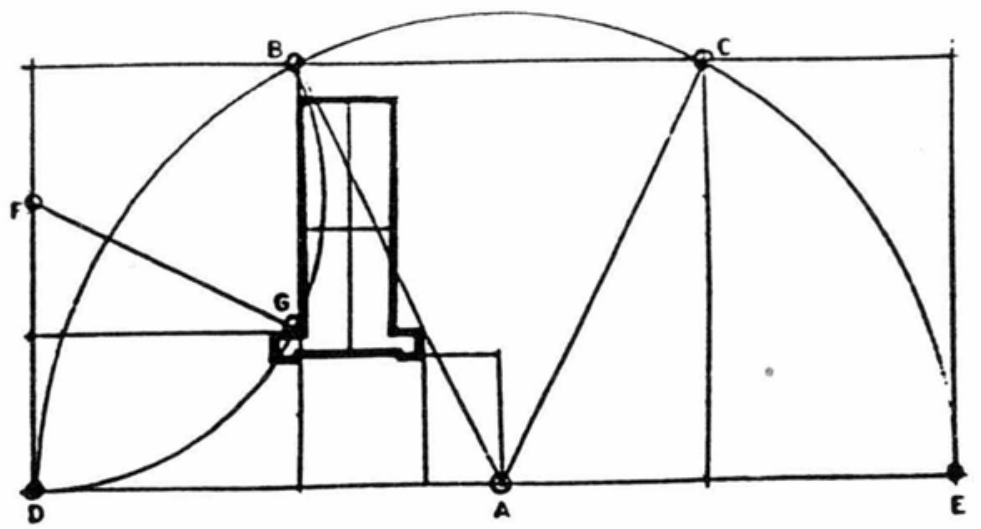

flgura no 3

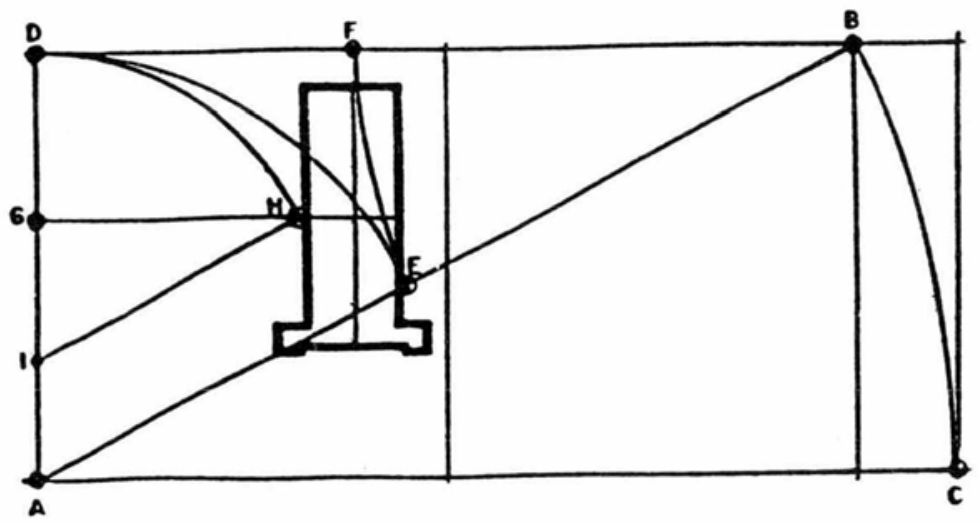

flguran: 4

Lámina 2. Esquema de la plaza con la ubicación de la catedral y la interrelación de trazos y secciones áureas. 


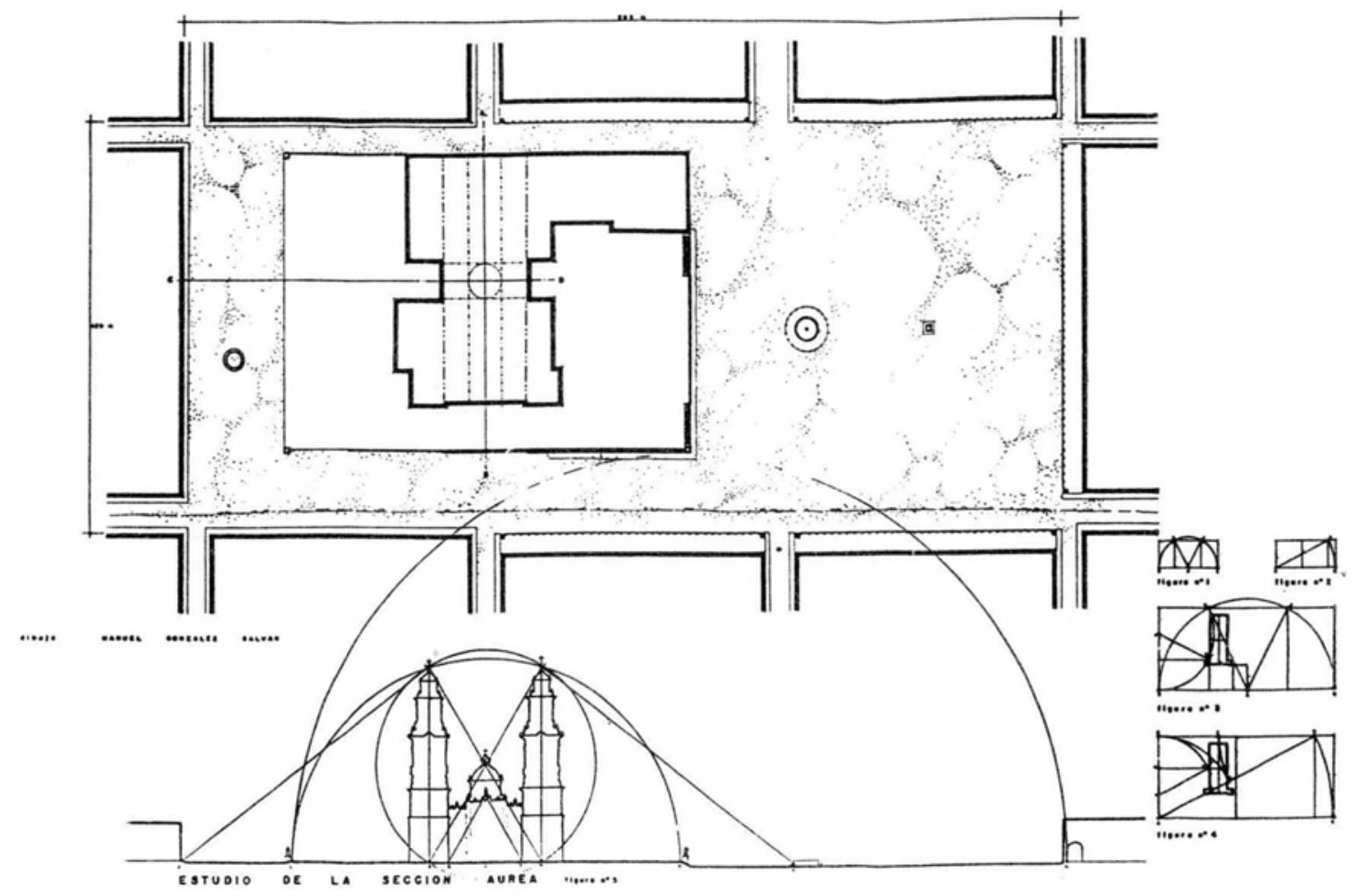

Lámina 3. Plano del conjunto de la Plaza Mayor, configurada en la época colonial con la presencia de la catedral dividiendo el área en espacios desiguales pero armónicos, lo que se acentúa con su propia colocación, dimensión y volúmenes, así como por los portales que circundan y marcan el espacio mayor o principal. 


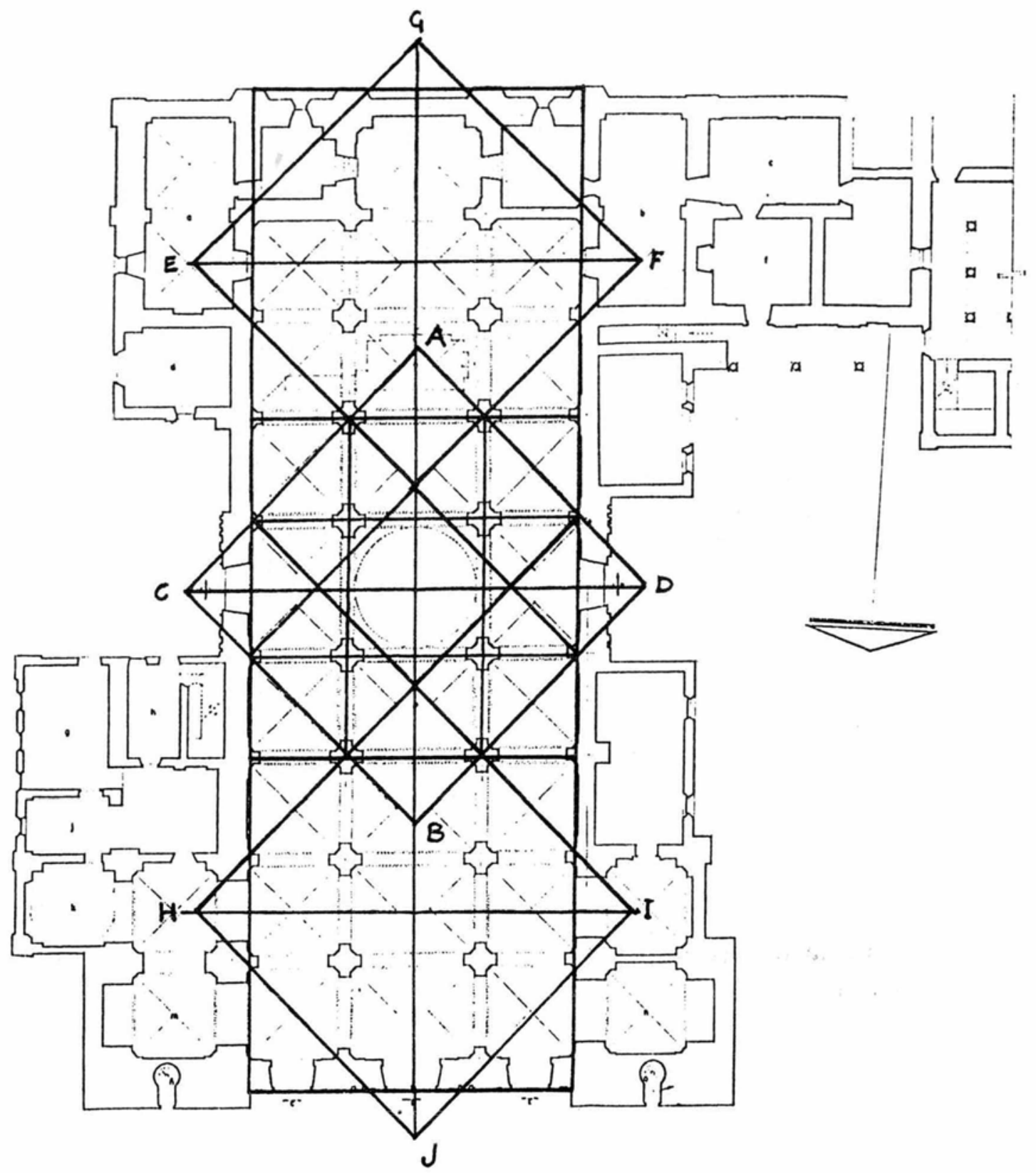

Lámina 4. Planta de la catedral con sus proporciones áureas y la aplicación del análisis de su geometría sacra. 
DOI: http://dx.doi.org/10.22201/iie.18703062e.1988.59.1402

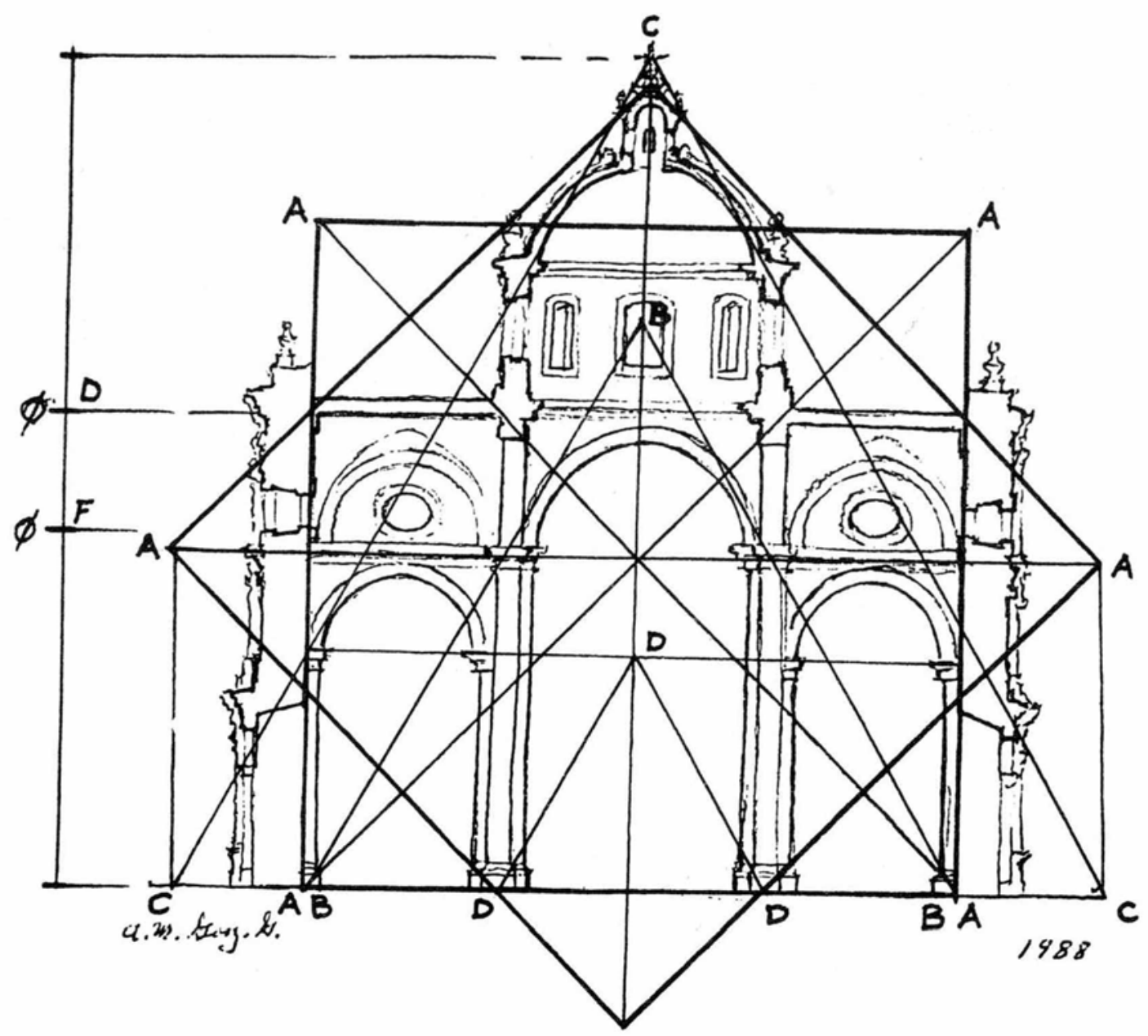

Lámina 5. Corte transversal de la catedral por el crucero, con secciones áureas y sacras en el alzado. 


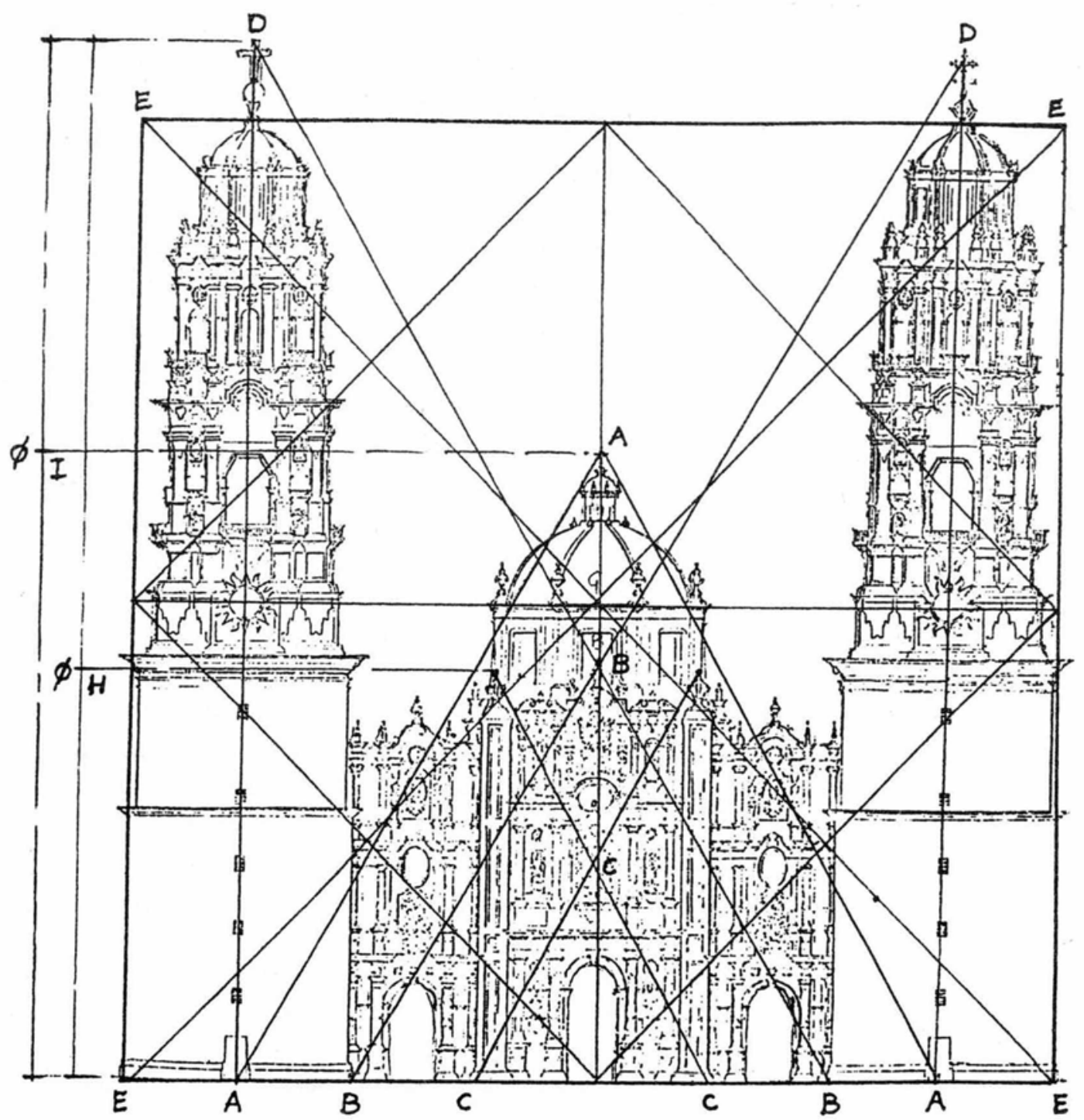

Lámina 6. Alzado frontal de la catedral con análisis de triangulación y geometría sacra, sección áurea y encuadramiento. 
tRAZADO dE LA PLANTA dE LA CAT EDPAL D. MORELIA.

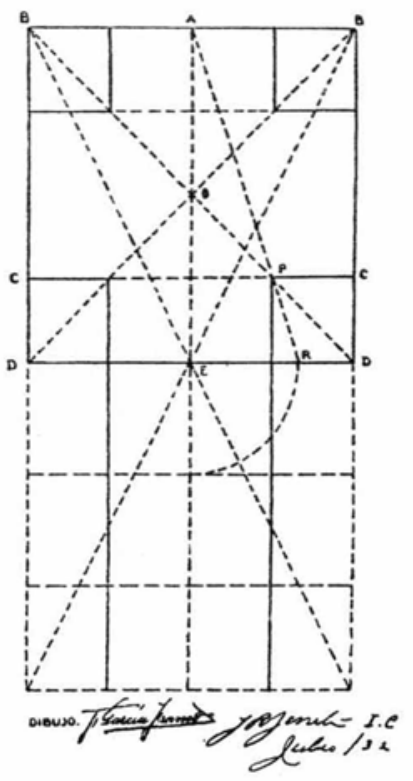

Lámina 7. Trazado de la planta de la catedral, según José R. Benítez. Especial atención merecen las opiniones del Ing. Benítez al considerar que, tanto en planta como en alzado, la catedral moreliana es desproporcionada e inarmónica. A nuestra manera de ver, su juicio crítico es equivocado por aplicar reglas de composición que al monumento no le corresponden. Además, siendo la construcción de una catedral obra de tanta relevancia, no es posible suponer que se construyera descuidando su grandeza estética y simbólica erigiéndola en forma "arbitraria", como lo asienta en su obra las catedrales de Oaxaca, Morelia y Zacatecas, pág. 25 a saber: "Morelia.La planta de este monumento, a nuestro juicio, fue trazada de una manera arbitraria. Fundamos nuestra opinión en que ninguno de los sistemas que seguimos para investigar las leyes geométricas a que se sujetó su trazado, ofrecen siquiera alguna semejanza con su proyección horizontal. En efecto, si adoptamos cualquier sistema de trazado y lo aplicamos a la planta de esta catedral, veremos que, cuando menos, su longitud resulta mayor en dos cláusulas, con relación a las proporciones que debería tener. El error de dar a la proyección horizontal del edificio una longitud mayor que la que debería tener, buscando falsamente suntuosidad, es causa de que en su perspectiva interior, la iglesia presente faltas de armonía." 
Lámina 8. Trazado del alzado de la catedral, según José R. Benítez. Al referirse a la elevación y fachada del templo, el Ing. Benítez también lo considera inarmónico y desproporcionado, quizá debido a equívocos en sus medidas, como lo prueban los errores que muestra la misma ilustración que comentamos en la relación de naves, cúpula y torres, en este alzado lo más digno de notarse es la envolvente cuadrada. Pero creemos que finalmente el Ing. Benítez ¡no supo ver la catedral!, o lo hizo prejuiciadamente hasta llegar a conclusiones adversas que nos parece son tan injustas como inacertadas. Con esta observación citamos, por último, su opinión del alzado catedralicio anotada en la pág. 50 de su misma obra. Las catedrales de Oaxaca, Morelia y Zacatecas, así nos dice: "Morelia. - tipo barroco, sin ningún carácter peculiar. Hay homogeneidad en la distribución de los motivos que la decoran. Sus proporciones son armoniosas en sus claros con relación a los macizos. Los lucernarios elípticos que están en los segundos cuerpos de las portadas laterales rompen la armonía de la composición. Junto a las enormes masas de las torres, la fachada de este templo se ve de proporciones raquíticas. Las torres pueden considerarse como tipos de solidez real y aparente. Su gran sobriedad y dimensiones dan idea de fuerza y resistencia a la vez, pero su falta de proporción con relación a la masa total del edificio las vuelve extravagantes y disformes a pesar de su suntuosidad y magnificencia".

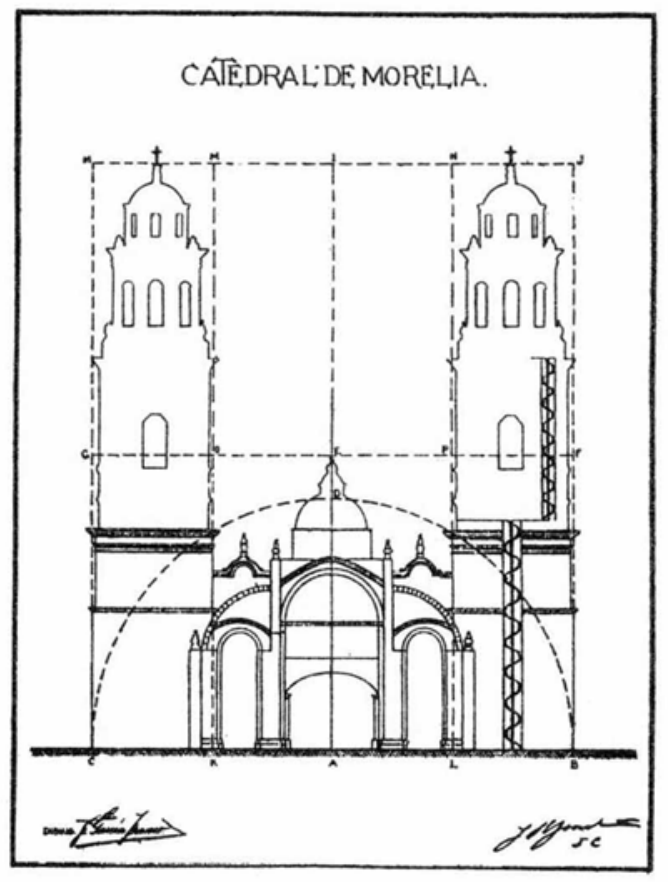




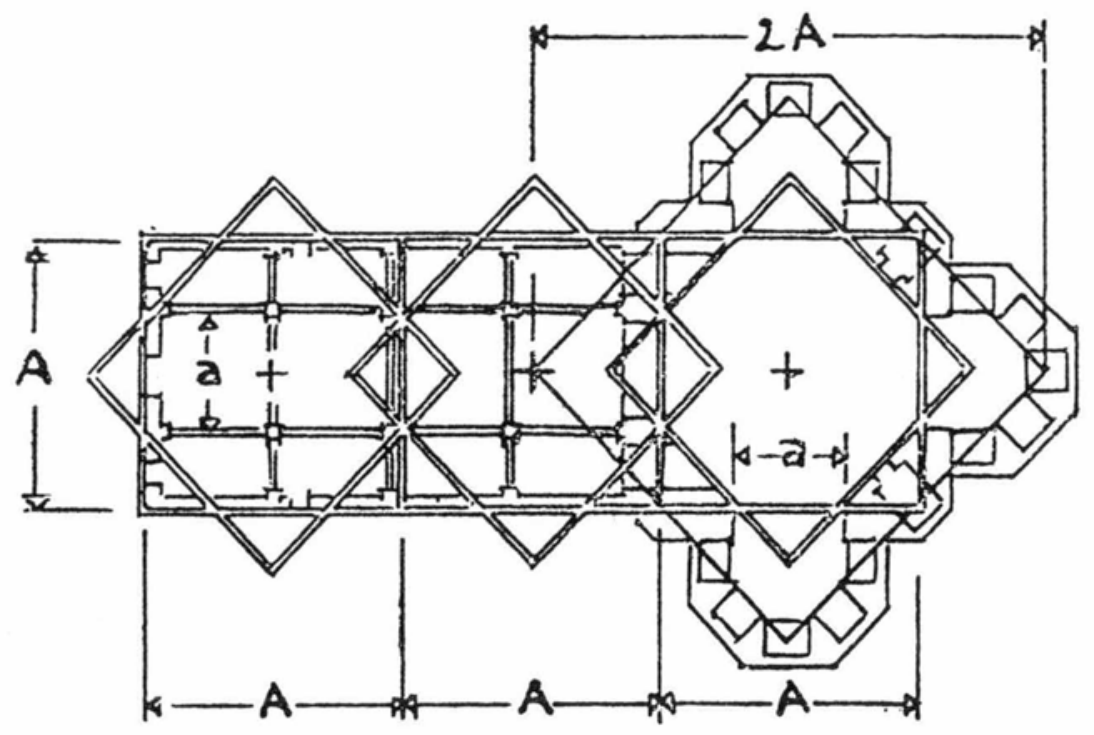

16. Cathedral, Florence.

Lámina 9. Plantas de la catedral de Florencia, Italia, y Nuestra Señora del Puerto, Clermont, Francia. Con geometría sacra aplicada.

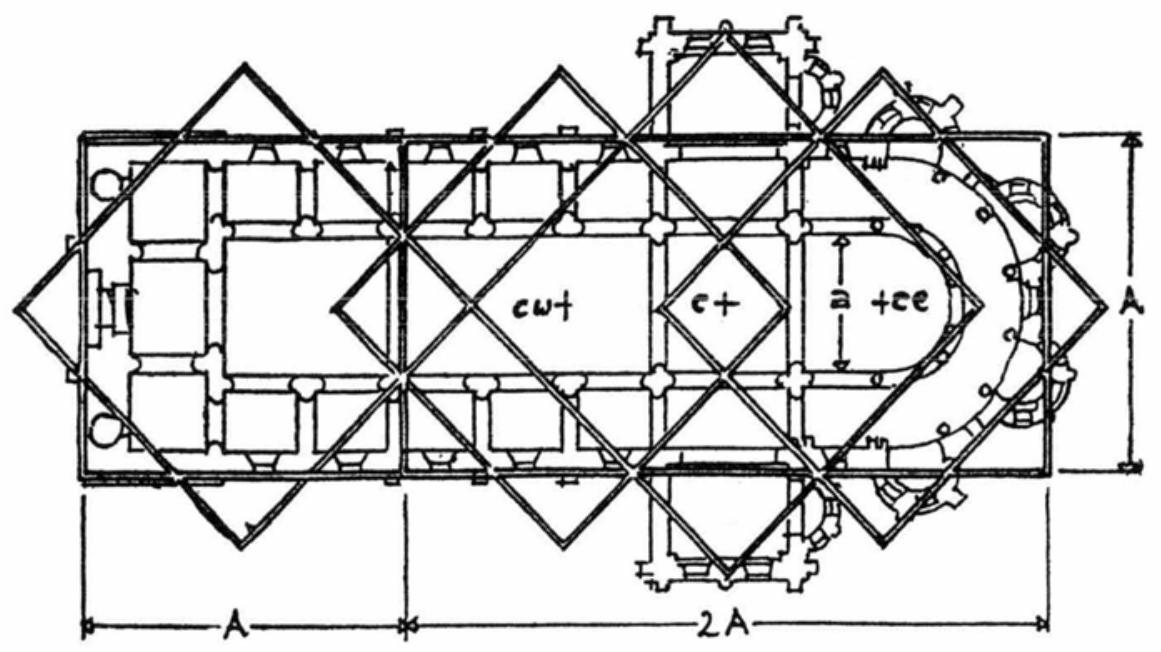

24. Notre Dame du Port, Clermont. 


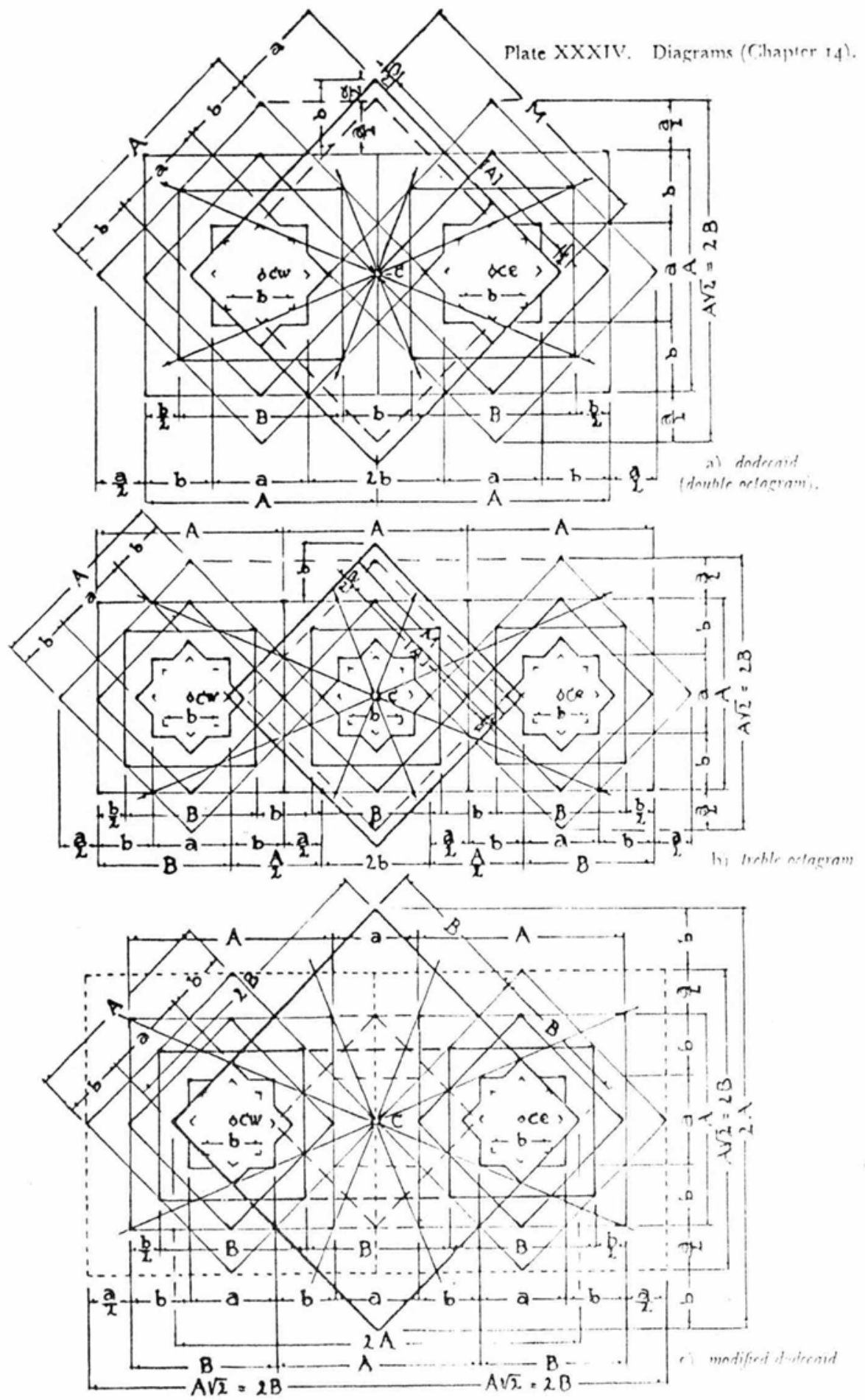

Lámina 10. Algunas variantes y posibilidades de diagramas para la aplicación de la geometría sacra y armónica según George Lesser. 
DOI: http://dx.doi.org/10.22201/iie.18703062e.1988.59.1402

LF a) Lübeck Cathedral(Chapter 19).

b) Schwerin Cathedral (Chapter 20).
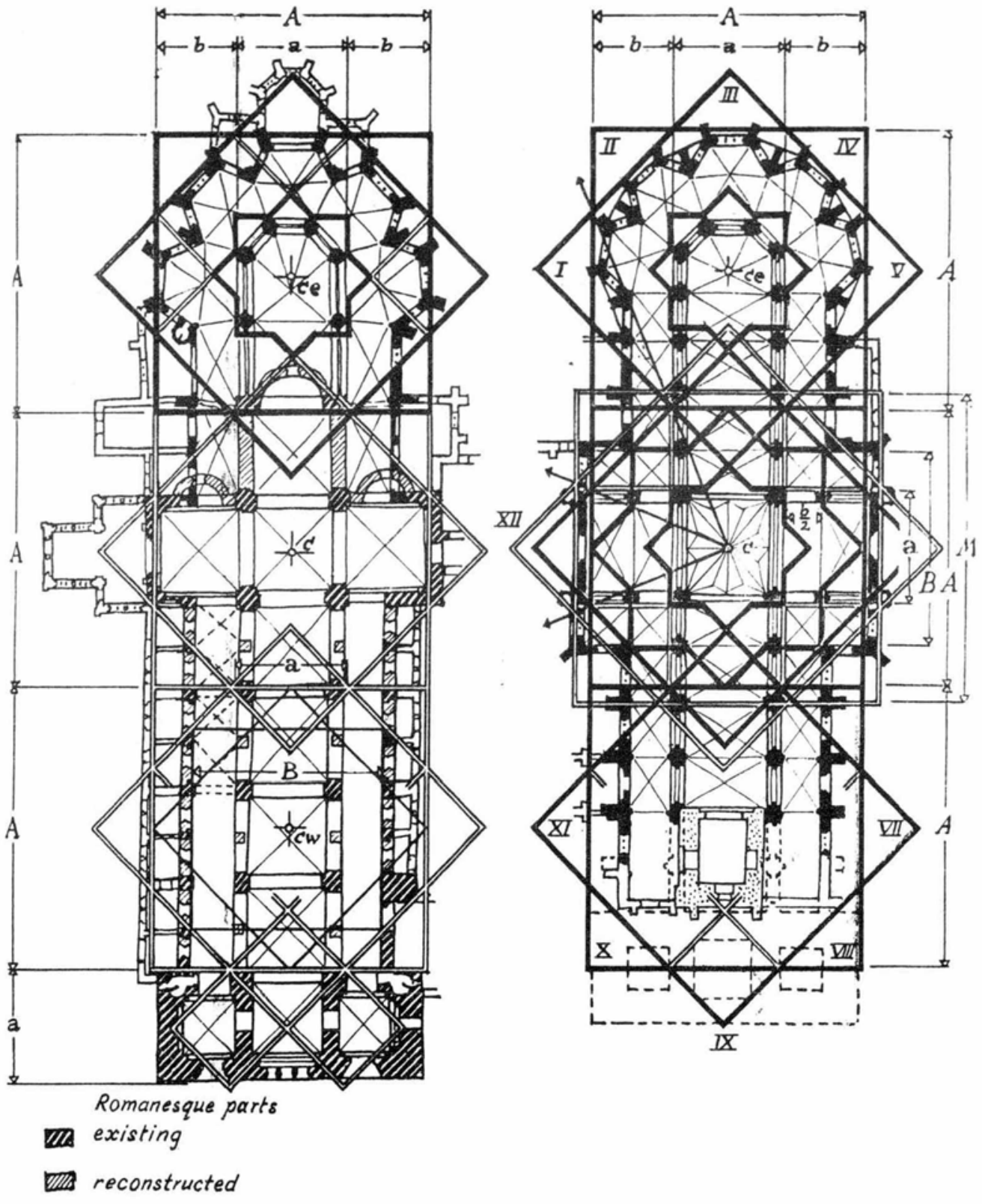

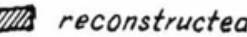

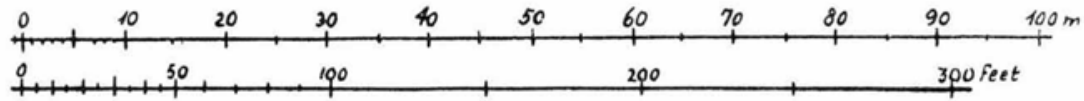

Plate XXXIX.

Lámina 11. Plantas de las catedrales de Lübeck y Schwerin en Alemania. Con geometría sacra y armónica aplicadas. 


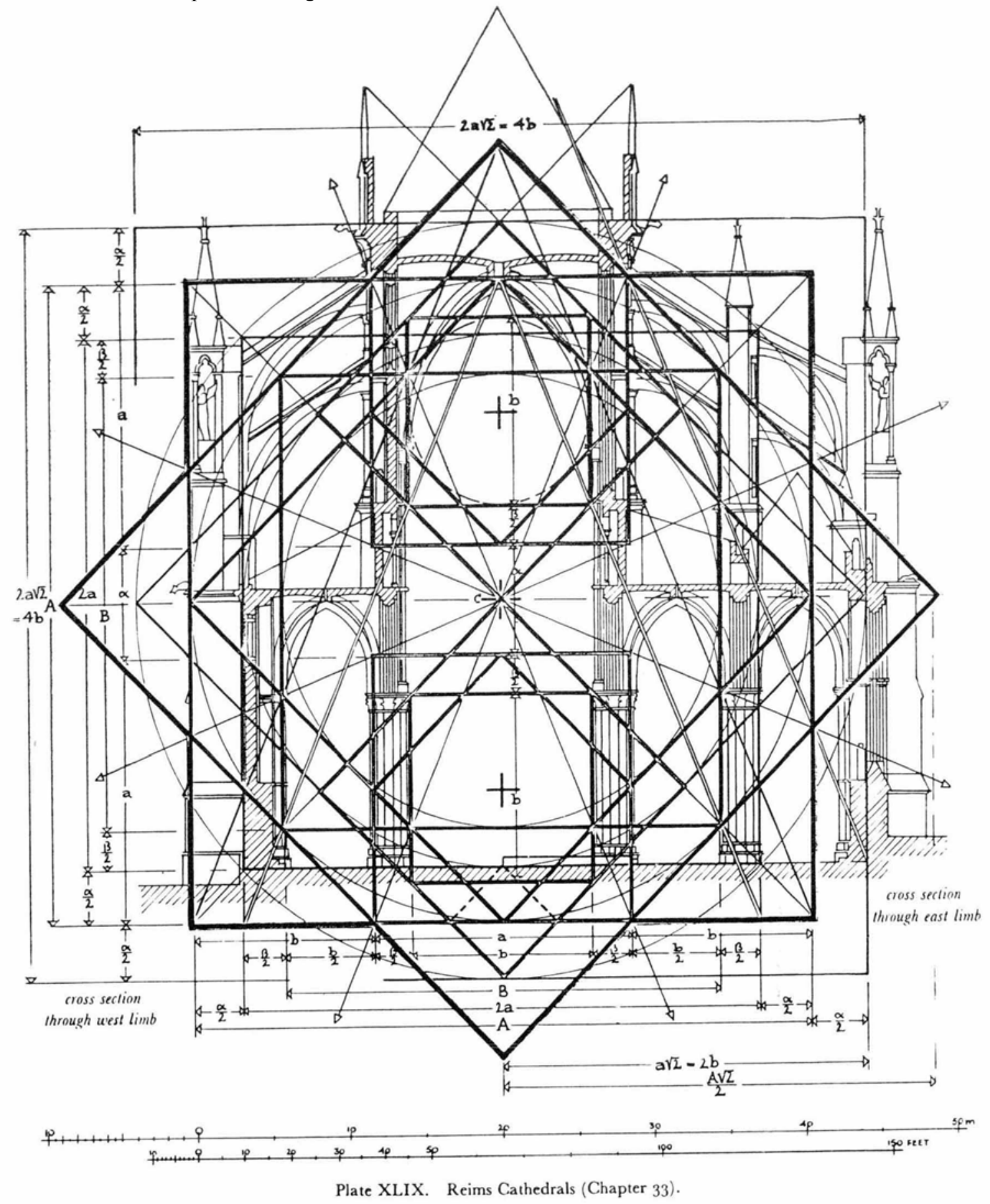

Lámina 12. Corte transversal de la catedral de Reims, Francia. Con análisis de geometría sacra y armónica en alzado. 
DOI: http://dx.doi.org/10.22201/iie.18703062e.1988.59.1402 
se ubiquen: sala capitular al oriente y sacristía al poniente de la cabecera $y$, en forma similar, cuatro capillas que hacen equilibrio y balance en volumen y espacio a los lados de la entrada, con lo que todo el conjunto queda sujeto a'la esencial "unidad en la variedad".

Es de notarse que aparte de las diez bóvedas de lunetos con que se cubren la nave mayor y cruceros, todo el resto: naves laterales, sacristía, sala capitular y capillas de la entrada, se cubren con un total de veintidós bóvedas de arista, lo que significa una intencionada propensión de los espacios catedralicios a la compartimentación cúbica interior.

\section{Situación urbana}

En 1543, cuando'el alarife - hoy diríamos urbanista- Juan Ponce tra* zó la ciudad, destinó un inmenso espacio para plaza mayor, constituido por un área rectangular de unos 130 metros de ancho por 296 de largo; medidas muy generosas, ya que, posteriormente, en 1576, las "Ordenanzas sobre descubrimiento nuevo y población" comúnmente conocidas como Cédula de Felipe II, recomiendan en forma previsora que la plaza mayor para nuevas ciudades que se funden, "teniendo respeto a lo que la población puede crecer, no sea menos de doscientos pies en ancho y trescientos de largo, ni mayor de ochocientos pies de largo y quinientos treinta y dos de ancho. De mediana y de buena proporción es de seiscientos pies de largo y cuatrocientos de ancho". La plaza moreliana, ya trazada en la fecha de la Ordenanza, supera tales medidas con sus aproximados 1055 por 467 pies castellanos.

La gran plaza, de 296 por 130 metros, queda sujeta por sus medidas, y en vastedad, a una serie de proporciones armónicas que se pueden comprobar si observamos algunas de sus interrelaciones (lám. 2).

En primer lugar configura lo que se llama un "rectángulo dinámico" marcable, en este caso (fig. 4), si se considera la anchura $\mathrm{AD}$, se duplica hasta el punto $B$, se toma la diagonal $A B$ y girada como radio hasta $C$, se delimita la longitud $\mathrm{AC}$, armónica y "dinámica" con relación al ancho $\mathrm{AD}$.

La longitud total de la plaza está a su vez subdividida por dos ejes de calles en el sentido norte-sur; ambos ejes, uno al oriente y otro al poniente, cortan en su longitud, por exactos puntos de "sección áurea", el gran espacio abierto.

Para localizar los puntos "áureos" tomemos el ancho AD como radio que, girado sobre la diagonal $\mathrm{AB}$, indica el punto $\mathrm{E}$ y éste, abatido sobre $\mathrm{DB}$, que equivale al doble de $\mathrm{AD}$, nos marca el punto $\mathrm{F}$, o "sección áurea" 
del área oriente de la plaza, y haciendo el trazo a la inversa se encuentra el punto con relación a la superficie poniente.

Ahora bien, cuando en 1660 Vicente Barroso de la Escayola proyecta e inicia la catedral, tomó sin duda en consideración la existencia de tales relaciones armónicas de la plaza, o al menos las "sintió" tan admirablemente que optó por una colocación magistral del templo, asombrosa por todos conceptos.

No tenemos conocimiento de la colocación precisa de la primitiva Iglesia Mayor de la ciudad, la que sirvió "de prestado" como catedral, sólo sabemos que era pequeña y debió ver hacia el poniente, como la mayoria de las iglesias procedentes del siglo XVI.

También ignoramos la intención original de cómo se iban a distribuir los portales en el perimetro de la plaza, pues todos los que existen son posteriores al inicio de la construcción catedralicia, pero lo que constituye un hecho indudable es que, con la presencia del gran edificio religioso, quedó definida, a partir de la segunda mitad del siglo XVII, la personalidad del centro urbano de Morelia (fig. 1).

Es digno de notarse lo acertado de la colocación de la catedral, pues el templo divide en dos partes desiguales, pero armónicas, la gran área de la plaza, con lo que el edificio tiene doble aprecio espacial y produce la sensación de que la ciudad posee dos plazas fundidas, o unidas por el eje "áureo" que denota en sí misma la nave mayor de la catedral; al oriente, el espacio abierto menor no es porticado, en tanto que al poniente se delimita perfectamente con el ritmo de las arquerías, danza y cabalgadura de variadas épocas y estilos, pero ya para siempre sujetos a un ordenamiento plástico (fig. 2 y lám. 3).

Por consecuencia de su colocación, es singular y único, entre las catedrales coloniales de México, que la fachada y el ábside rematen la pers. pectiva de dos calles, las que curiosamente $\longrightarrow$ intencionalmente?parecen prolongarse hasta el corazón del templo, pues sensiblemente el ancho de estas dos calles y el de la nave mayor son iguales; unos diez pasos.*

Igualmente, podemos observar el equilibrio armónico en la colocación catedralicia, como lo podemos comprobar en el crucero de la iglesia (lám. 2, fig. 4), ya que se encuentra precisamente a la altura de la línea GH o "sección áurea" del ancho $\mathrm{AD}$ de la plaza, por lo que la cúpula se encuentra exactamente sobre el punto de cruce y confluencia de los principales

* La catedral de México hoy tecibe de frente la Av. 20 de Noviembre, pero no debe. mos olvidar que esto se debe a una moderna alteración urbana. 
ejes armónicos y relaciones espaciales estéticas, de manera que su esfericidad polariza e irradia a la vez, como en un sistema de relaciones orbitales, todo el movimiento plástico externo de la plaza e interno del templo, y así el crucero de la catedral es el inobjetable corazón de la ciudad que bellamente deja sentir el latir de su vida rítmiica con la diástole de lo externo y civil, en armonía con el sístole interno y religioso: materia y espíritu en equilibrio.

\section{Catedrales de costado}

Puesto que aquí tratamos de apuntar peculiaridades urbanas, cabe señalar una constante que puede observarse en la colocación de las catedrales mexicanas establecidas en el siglo XVI. Tal constante se basa en la predilección por colocar de costado a las plazas mayores o civiles, el volumen del templo, y sin que esto sea privativo de México, sí es lo usual en tan significativos monumentos como sede episcopal, dentro del contexto de nuestras ciudades, sin que escape a ello la de Morelia.

A lo anterior debemos añadir que, en todos los casos, se cumple el ordenamiento de la Cédula de Felipe II en el artículo ciento veinte:

Para el templo de la iglesia mayor, parroquias o monasterios, se señalen solares, los primeros después de la plaza, y sean en isla entera, de manera que ningún edificio se le arrime, sino el perteneciente a su comodidad y ornato.

Con excepción de México, Mérida y Durango, las catedrales coloniales están de costado a la plaza, como las de Guadalajara, Puebla, Morelia, Oaxaca y Chiapas. Con tal situación, la manificencia de sus fachadas principales voltea el rostro a escasos, o nulos, atrios fronteros, como desentendiéndose de los grandes espacios dedicados a las actividades puramente laicas (figs. 3 y 4).

Aunque sería difícil de probar, sí es posible que esta volumetría transversal tenga algún sentido alegórico, ya que la Iglesia muestra en esta forma la grandeza de "el Cuerpo Místico" que alude a Cristo, pues Él mismo se comparó con el templo de Jerusalén cuando dijo:

Destruid este templo, y en tres días lo levantaré. Replicaron los judíos: "Cuarenta y seis años se han empleado en edificar este templo ¿y tú yas a levantarlo en tres días?" Pero El hablaba del templo de su Cuerpo. Cuando resucitó de entre los muertos se acordaron sus discípulos de que había dicho 
esto, y creyeron en la Escritura y en la palabra que Jesús había dicho. (San Juan, cap. II, 19-22).

Es innecesario ponderar la importancia de esta cita evangélica, pues ella dio lugar, en toda la historia del arte cristiano, a una directa alusión simbólica entre los templos y el Cuerpo de Cristo, hasta con las evocaciones antropomorfas que eran tan usuales, y siguen vigentes, de cabecera, pies y brazos, del crucero, es decir el todo de un cuerpo orgánico, y no sólo un rostro o fachada (fig. 4).

También era, y es común mencionar, el "barco" o nave mística como símbolo del perenne avance de la Iglesia al través de los tiempos, y esta espiritual navegación se sugiere y aprecia mejor contemplando las naves de costado, que así es normal representarlas, y no de proa a popa.

Como solución plástica, calificaríamos tan reiterada y consciente situación urbana de tipo o estilo manierista, ya que el anterior renacentismo y el posterior barroquismo dieron preferencia a la espectacularidad de las perspectivas con espacios de convergencia frontal.

\section{Proporción y símbolo}

En tiempos novohispanos, cuando se aprobaban los planos para alguna importante obra arquitectónica, en la que se suponía que la magnitud requeriria tiempo prolongado y posibles distintas intervenciones, como lo es emprender la consrucción de una catedral, buen cuidado tenían las autoridades y los peritos en que ésta quedara sujeta a un acertado proyecto que fuera rector de su belleza y garantía de que la intención expresiva pudiera llevarse al cabo.

Así, cuando el virrey aprueba los planos y ordena la construcción de la catedral - previo análisis y discusión del proyecto por peritos, entre los que se contaba Luis Gómez de Trasmonte, entonces maestro mayor de la catedral de México-, en la aprobación se asienta que la traza está "hecha y ajustada a las medidas de buena arquitectura".*

Por otro lado, sabemos también que el cuidado que se tenía por las buenas medidas, o sea por las armónicas proporciones, no atendía tan sólo a una intención puramente esteticista, sino que, especialmente tratándose de un gran templo, su belleza, en conjunto y en detalle, debiera tener un mensaje que comunicarnos, un alma primordial coordinadora del todo,

* Archivo General de Indias. México, 1052, "Mandamiento del virrey duque de Alburquerque", marzo 2 de 1660. 
como había sucedido en las grandes catedrales medievales, cuya prolongación en América, y en la historia del arte sacro cristiano, 10 constituyen las que España erigió en el Nuevo Mundo.

Sabemos también que las "mediclas de buena arquitecrura", usuales en el tiempo de construcción de la catedral moreliana, se basaban en un abundante legado de sistemas para proporción y armonía, enriquecido sobremanera por tratadistas de la época renacentista, por lo que podrían aplicarse varios de ellos en búsqueda de la razón de ser plástica de la catedral, pero optamos aquí mejor por mostrar, únicamente, la nítida respuesta que el monumento da a ciertas reglas de geometría sagrada que provienen de la Edad Media y han nutrido secularmente la creación del arte cristiano. Fórmulas de elevada sugestión religiosa, en apariencia invisibles pero comprobables, que animan los volúmenes y espacios de los más emotivos monumentos creados por la fe en lo trascendente.

Diremos que, básicamente, tres figuras geométricas hemos aplicado como señuelo alegórico o red de captura al imponderable espíritu religioso que en conjunto la catedral nos deja sentir; ellos son, a saber:

El círculo y la esfericidad como símbolos de perfección divina y eternidad; sin principio ni fin.

El cuadrado como símbolo de lo terrenal por su clara delimitación en cuatro extremos; por eso, cuando en él se aloja el círculo, se alude a lo divino en la tierra o sea, concretamente, a Cristo encarnado. Y si el cuaàado gira sobre sí mismo, es como la tierra activada, animada o espiritualizada. Muy relevante es la simbología de la consecuencia tridimensional del cuadrado, o sea el cubo, ya que en el arte cristiano ésta tiene resonan" cias bíblicas y representa lo que es del agrado divino, pues los recintos cúbicos se piensan como lugares santos por excelencia; recordemos que Salomón, para perpeutar la tienda en que se guardaba el Arca de la Alianza, al construir el templo de Jerusalén hizo el Sancta Sanctorum precisamente cúbico; así:

El debir tenía veinte codos de largo, veinte codos de ancho y veinte codos de alto. (Reyes, 1-6. 20).

También debemos recordar que El Escorial, el gran monumento simbolo de España, erigido durante la segunda mitad del siglo XVI, ejerció una grande y directa influencia en la construcción de las catedrales hispanoamericanas que le son contemporáneas o inmediatamente posteriores, como la de Morelia, y al Escorial su cronista, fray José de Siguienza, lo llamó, "otro templo de Salomón", tanto que la composición del insigne conjunto 
en que predominan cuadrados y formas volumétricas y espaciales cúbicas no es pura coincidencia, sino que hay intencionales alegorías de su autor, el arquitecto Juan de Herrera, quien hasta escribió un significativo Discurso de la figura cúbica, cuyo manuscrito se conserva en la misma biblioteca escurialense.

Por último, el triángulo equilátero, por sus tres lados y ángulos iguales formando unidad, es símbolo del esencial Misterio de la Trinidad dentro de la doctrina cristiana; por tanto, una de las figuras geométricas más usuales para la composición y sugestión plástica que considera a Dios presente aun cuando no se le vea.

Especialmente la arquitectura gótica empleó el triángulo equilátero para erguirse, de modo que el arco apuntado llamado "normal", no es más que un triángulo equilátero cuya base, girada como radio hacia el vértice, acoge y exalta esta primordial figura; y en la catedral moreliana fachada, cúpula y torres tienen relaciones de triangulación equilátera que muy bien se estructuran con tan invisible como virtual cimbra sagrada.

$\mathrm{Y}$ véamos qué nos dicen las tradicionales formas de aprecio arquitectónico en planta, sección o corte y alzado con que podemos configurar la imagen más aproximada a la vivencia y aprehensión arquitectónica que sólo en el contacto directo del fuera y el dentro, el entrar y salir, el ir y venir físicamente en torno a él nos puede ofrecer un monumento como lo es la catedral de Morelia, sin olvidar en ningún momento, como premisa de referencia, que el Titular o Patrocinio del edificio es La Transfiguración de Cristo, o sea la manifestación de la Divinidad del Salvador ante sus discípulos y por ende tanto del Misterio Trinitario como de las dọ naturalezas cristológicas: la divina y la humana.

\section{La Planta}

Sin más comentarios que subrayar ciertos puntos, o líneas primordiales, consideremos la planta (lám. 4).

$\mathrm{Si}$ tomamos como medida inicial de proporción el ancho interno del templo, o sea la dimensión del crucero, y con esta dimensión trazamos un cuadrado, podemos apreciar cómo la relación de ancho y largo del edificio es uno a tres, de manera que tres cuadrados iguales, alineados, marcan la dimensión total del monumento, y así los tres círculos que pueden inscribirse dentro de estos cuadrados son tangentes en una secuencia que inserta sus centros en un solo eje marcado por la nave mayor.

Los centros de los tres cuadrados 'marcan puntos óptimos y significativos en el aprecio espacial y ritual del interior; de ellos sólo es perceptible ac- 
tualmente, en toda su importancia, el que corresponde al crucero, bajo la cúpula, en la línea transversal $\mathrm{CD}$. Con la supresión del antiguo coro, que estuvo en medio de la nave mayor, se ha desvirtuado el punto central de referencia correspondiente al eje transversal HI, que entre las capillas de El Sagrario y Porta Coeli reposaba frente al desaparecido altar del Perdón. También queda en la actualidad distorsionado el aprecio espacial de la cabecera del templo, porque el tramo central del eje transversal EF, correspondiente al deambulatorio original, está obstruido e invadido, como prolongación del actual coro, por lo que las naves laterales no pueden cumplir su programada y primitiva función procesional, ni pueden polarizarse correctamente, como antes sucedía en este sitio, las relaciones de altar mayor en la nave y altar de los Reyes en el ábside y de la Sacristía y Sala Capitular. Pero no obstante las pérdidas y alteraciones, aún puede percibirse, en la distribución de la planta catedralicia, un orden y proporción que responden armónicamente a su primigenio planteamiento litúrgico y alegórico.

Es más; si sobre sus respectivos centros se giran cuarenta y cinco grados los tres cuadrados que dimensionan la catedral, podemos observar cómo las intersecciones que producen sus caras, así como la situación de sus ángulos, generan puntos de relación armónica en lo dimensional, a la vez que de sobresaliente referencia plástica y ritual. Esto es muy notable en la parte central o del crucero, donde los puntos de intersección de las caras unidas entre sí marcan justamente la relación de anchuras entre nave mayor, crucero y naves laterales, así como la ubicación del centro de pilastras, curso de los arcos y trazo de la cúpula.

También en forma plástica, elocuente y armónica, los ángulos de los cuadrados activados 0 en giro, enfatizan los lugares de mayor jerarquía, como son:

A. El altar mayor y presbiterio.

B. El lugar del antiguo coro con su sillería y el sitio de honor para la cátedra o sede episcopal y el trascoro con el altar del Perdón; elementos todos desaparecidos.

C. Portada oriente del crucero dedicada a la Virgen de Guadalupe.

D. Portada poniente del crucero dedicada a San José.

E. Entrada y parte central o eje de la sala capitular.

F. Entrada y parte central o eje de la sacristía.

G. El ábside como remate visual interno y externo.

H. Capilla del Sagrario.

I. Capilla de Porta Coeli.

J. Portada Mayor o de La Transfiguración. 


\section{Corte o sección}

El corte o sección por el crucero también nos muestra una elocuente armonía donde los alegóricos cuadrados, círculos y triángulos equiláteros se presentan en urdimbre invisible pero sensible como trama estética sugeridora de símbolos (lám. 5).

$\mathrm{Si}$ volvemos a tomar el ancho interno del templo, considerándolo dimensión de partida, como se hizo para el aprecio de la planta, podemos observar en el alzado abundantes interrelaciones armónicas, de las cuales vale destacar las más notables y que apuntamos a continuación.

En primer lugar, el cuadrado de extremos marcados por los puntos $\mathrm{A}, \mathrm{y}$ su igual activo o en giro delimitan, en los puntos de intersección de sus caras, ejes y líneas de composición tan importante como son las que rigen, dimensionan y proporcionan la relación de anchuras y alturas entre las naves y la cúpula, como se aprecia en el esquema, de modo que se genera un espacio interno que, aunque plural de acuerdo con su barroquismo, se sintetiza bajo la cúpula en imponderable esfericidad cuyo centro ingrávido se localiza sensiblemente en coincidencia con los capiteles corridos de la nave mayor y crucero, así como del centro de trazo y arranque de los arcos torales, también de la nave mayor y crucero, y en consecuencia con el centro espacial y corazón virtual del monumento.

Por su lado, la alusión trinitaria se hace perceptible si retomando el ancho interno de base se levanta el triángulo equilátero de ángulos marcados en $\mathrm{B}$ y comprobamos que el vértice coincide con la parte media del tambor y ventanas de la cúpula; por tanto, con su centro espacial y lumínico. Además, los dos lados elevados del triángulo se cruzan con el eje de los pilares a la altura de los capiteles, o sea en la parte más significativa, estructuralmente hablando, de todo el espacio interno, ya que en este nivel se traba y equilibra la mayor parte de lo sustentado —arcos, bóvedas y cúpula - con lo sustentante - pilares y muros- siendo también la zona promedio en que convergen los mayores ejes del espacio interno; horizontalmente lo longitudinal y transversal de nave mayor con crucero y verticalmente el de la cúpula que los anuda.

Un triángulo equilátero menor, de base equivalente al ancho de la nave central, considerada la distancia entre el eje de pilares entre los puntos D, marca con su vértice la miład de la altura que alcanzan las bóvedas mayores, a la vez que la línea de capiteles para el arranque de arcos en las naves laterales.

Un tercer triángulo equilátero, de base igual a la diagonal de los cuadrados envolventes $\mathrm{A}$, eleva externamente su vértice $\mathrm{C}$, a la altura total 
de la cúpula, incluyendo la cruz, de manera que el trazo de la media naranja y linternilla de ella quedan insertas en un último y cimero triángulo equilátero cuya base es, sensiblemente, el diámetro interno sobre el tambor.

Es de notarse también que la "sección áurea" de la altura total por el eje vertical del crucero, marca justamente, en el punto $D$, la elevaoión de la nave mayor y crucero en relación a la altura de la cúpula en sí y, en sentido inverso, la altura de los pilares $F$ está en áurea sección con el punto en que el impetu de la cúpula eleva externamente la cruz.

\section{Alzado externo}

La composición y volumetría exteriores de la catedral prolongan y expanden por los infinitos ángulos visuales del paisaje urbano una coherente y cohesiva armonía tejida entre hilos invisibles, aunque perceptibles, de alegóricas geometrías en que se reiteran cuadrados, círculos y triángulos equiláteros.

De entre ellos procuramos extraer las líneas más fácilmente observables, amplias y envolventes que tanto se pueden seguir del todo hacia las partes, como de éstas hacia el conjunto, ya que para captar una feliz armonía no se puede prescindir de esta reciprocidad.

Pero al considerar el lógico y cronológico proceso constructivo del templo, apreciémoslo como se fue realizando hasta su esplendoroso término.

Como fachadas y torres fueron lo último que se hizo, resulta natural apreciar el desarrollo del edificio casi como el de un organismo vivo, y así creció de dentro hacia afuera; por tanto, volvemos a considerar básico para el exterior el desplante interno que se refleja en los triángulos equiláteros de ángulos A, B y C (lám. 6).

El triángulo $A$ tiene como base la distancia entre ejes de las torres y equivale a la diagonal del cuadrado en giro del ancho interior del templo, su vértice es la altura de la cruz en la cúpula.

El triángulo $B$ rige propiamente $\mathrm{la}$ fachada de las naves, su base es la distancia entre los cubos de torres y equivale al ancho interno, su vértice da justamente al término del remate central de la fachada y al desplante de los campanarios, mientras la prolongación recta de sus caras elevadas se cruza con el eje de las torres precisamente en la altura marcada por las cruces $\mathrm{D}$, por lo que el triángulo equilátero que delimita la fachada, al expanderse, proporciona y sujeta la volumetría de las torres en unciosa y acentuada verticalidad y, al contraerse o reafirmarse, en su más íntima razón interna se acendra en el triángulo $\mathrm{C}$, más breve e intenso, que toma como base el ancho de la portada central y su vértice puntualiza nada me- 
nos quie la figura de Cristo en el relieve del patrocinio catedralicio, o sea el de La Transfiguración.

Así, estas proporciones estético-religiosas logran un solemne y majestuoso equilibrio de emociones plásticas entre lo centrifugo y lo centrípeto, un barroco de proclama y veneración, de acción y contemplación que tiene como fondo de referencia la evangélica revelación del Misterio Trinitario.

Además, no falta la serena sugestión del cuadrado que envuelve la totalidad de los volúmenes frontales y los polariza en relación con la esfericidad centralizante de la cúpula. Así se muestra el entorno del cuadrado $\mathrm{E}$, donde el ancho total de la base del templo, incluyendo los cubos de torre, es igual a la altura de éstas sin las cruces que las rematan. Las diagonales del mismo cuadrado se cruzan a la altura G, terminal del tambor de la cúpula y en el punto central de la media naranja, en tanto la horizontal que pasa por este nivel, en su encuentro con el eje de las torres indica la posición de las carátulas de los relojes. De esta manera, consecuentes líneas secundarias van cerrando el tejido compositivo con monumental belleza, fecunda hasta en los últimos detalles ornamentales.

Por último, puede observarse que, en alturas, la de la fachada en su término $\mathrm{H}$ está en sección áurea con relación a la elevación total de las torres y en sentido inverso a la relación áurea que al nivel I guardan entre sí las cruces que finalmente rematan cúpula y torres.

Muéstrase, pues, la catedral moreliana pletórica de armonía y proporción, tanto en el trazo de su planta y alzado interiores como en la elevación de volúmenes exteriores. Trazos y proporción cuyo producto armónico final creemos así sugerido y sugerente de un sutil mensaje arquitectónico rico en contenido simbólico sacro.*

\section{Crédito de IluUstraciones}

Las figuras 1 y 2 proceden del archivo del autor; la 3 es litografía del siglo XIX que representa la catedral de Morelia en 1830 , y se reprodujo en la revista literatria El Hijo pródigo, No. 52, noviembre de 1945; la 4 es fotografía de Mina Ramírez Montes en la Fototeca del IIE.

Para las láminas, ver la bibliografía, pues de ahí es su mayor procedencia; a saber:

1. Planta de la catedral, tomada del Catálogo de construcciones... de Morelia, de Esperanza Ramírez Romero.

* Véanse láminas complementarias. 
2. Esquema de la plaza y ubicación de la catedral con sus secciones áureas, del Estudio y proyecto para la plaza mayor de Morelia, Manuel González Galván.

3. Plano del conjunto de la plaza mayor, del antes citado Estudio y proyecto ... con planos del autor.

4. Planta de la catedral con sus secciones áureas y sacras, análisis del autor sobre el plano tomado del Catálogo de construcciones...

5. Corte transversal por el crucero con secciones áureas y sacras, es croquis a escala, del autor.

6. Alzado frontal de la catedral con triangulación y encuadros, análisis del autor sobre levantamiento tomado del Catálogo de construcciones...

7. Trazado de la planta de la catedral, según José $\mathrm{R}$. Benítez, tomado de Las catedrales de Oaxaca, Morelia y Zacatecas.

8. Trazado del alzado de la catedral, según José R. Benítez, tomado de Las catedrales de Oaxaca, Morelia y Zacatecas.

9, 10, 11 y 12 provienen de la obra Gothic Cathedrals and Sacred Geometry de George Lesser, en el siguiente orden:

9. Volumen I, páginas 43 y 159.

10. Volumen II, lám. XXXIV.

11. Volumen II, lám. XXXIX.

12. Volumen II, lám. XLIX.

\section{BIBLIOGRAFIA}

BenÎtez, José R., Las catedrales de Oaxaca, Morelia y Zacatecas. Arqueografia de las catedrales. Talleres Gráficos de la Nación, México, 1934.

González Galván, Manuel, Estudio y proyecto para la Plaza Mayor de Morelia. Gobierno de Michoacán y Departamento de Turismo. Fimax Publicistas, Morelia, 1960.

Catedral de Morelia. Monografías de Arte Sacro. Núm. 10-11. México. Agosto 1981 -Febrero 1982.

Lesser, George, Gothic Cathedrals and Sacred Geometry. Dos volúmenes. Alec Tiranti, Londres, 1957.

RAMíREZ Montes, MINA, La escuadra y el cincel. Documentos sobre la construcción de la cotedral de Morelia. IIE, Monografías de Arte 7, UNAM, México, 1987.

Ramírez Romero, Esperanza, Catálogo de construcciones artísticas, civiles y religiosas de Morelia. Coedición de la Universidad Michoacana de San Nicolás de Hidalgo y FONAPAS MICHOACAN, México, 1981.

Silva Mandu jano, Gabriel, La catedral de Morelia. Arte y Sociedad en la Nueva España. Comité Editorial del Gobierno del Estado, Instituto michoacano de cultura, México, 1984. 